\title{
Phosphorylation State-Responsive Lanthanide Peptide Conjugates: A Luminescence Switch Based on Reversible Complex Re-organization
}

\author{
Matthew S. Tremblay, Qing Zhu, Angel A. Martí, Joanne Dyer, Steffen \\ Jockusch, Marlin Halim, Nicholas J. Turro, and Dalibor Sames* \\ Department of Chemistry, Columbia University, \\ New York, New York 10027
}

\author{
Part I: Synthetic Methods \\ Part II: Steady State Emission Measurements \\ Part III: Time Resolved Emission Measurements \\ Part IV: ${ }^{31}$ P NMR \\ Part V: Mass Spectrometry \\ Part VI: Enzyme Assays
}

Part I: Synthetic Methods

\section{General}

Fmoc amino acids, Rink Amide AM resin, and all coupling reagents used were purchased from NovaBiochem. All other chemicals were purchased from Sigma-Aldrich, Acros, or Strem and were used as received. Solvents were purified by being passed through a column of alumina under an argon atmosphere and used without further purification. Preparative HPLC was performed on a Vydac C18 Protein \& Peptide column with a Waters 600 Controller; fractions were detected with a Waters 2487 Dual $\lambda$ Absorbance Detector and data was analyzed using OpenLynx software.

\section{Peptide Synthesis}

Synthesis of diethylenetriaminepentaacetic acid (DTPA) conjugated peptides was accomplished using manual Fmoc-based solid phase peptide synthesis on Rink Amide AM resin $(0.7 \mathrm{mmol} / \mathrm{g})$ using diisopropylethylamine (DiPEA), O-(benzotriazol-1-yl)N,N,N'N'-tetramethyluronium tetrafluoroborate (TBTU), hydroxybenzotriazole (HOBt), and the appropriate Fmoc amino acids, which were purchased and used with the side chains protected as recommended. ${ }^{1}$ DTPA was introduced to the N-terminus using the tetra-t-butyl protected derivative $\operatorname{DTPA}(t-\mathrm{Bu})_{4}$, which was synthesized according to a

\footnotetext{
${ }^{1}$ Ser: $t$-butyl; Tyr: $t$-butyl; Arg: pentamethyl benzofuran (pbf); Asp: $t$-butyl; Glu: $t$-butyl; phosphoSer: $\mathrm{P}(\mathrm{O})(\mathrm{OH}) \mathrm{OBzl}$; phosphoTyr: $\mathrm{P}(\mathrm{O})(\mathrm{OH}) \mathrm{OBzl}$.
} 
reported procedure ${ }^{2} ;\left[\operatorname{EIDA}(t-\mathrm{Bu})_{2}\right]_{2} \mathrm{Gly}$ was prepared as reported. ${ }^{3}$ Coupling reagents (TBTU, HOBt, and Fmoc-AAs) were used in 3-5 fold excess relative to the resin loading and DiPEA was used in 2-3 fold excess relative to the coupling reagents. Coupling steps were carried out at ambient temperature in dry dimethylformamide (DMF) for 1-3 $\mathrm{h}$ and Fmoc deprotection was carried out in 20\% (v/v) piperidine/DMF for 15-30 min. After being agitated on a wrist-action shaker for the appropriate reaction time, the resin was washed with dichloromethane (DCM) and DMF (3x each) and used immediately for the next phase of synthesis, or washed with methanol $(\mathrm{MeOH})$, dried under high vacuum, and stored in a dessicated container at $-20^{\circ} \mathrm{C}$ until later use. The peptide was cleaved from the solid support and globally deprotected by stirring the dry resin with trifluoroacetic acid (TFA) containing $2.5 \% \mathrm{H}_{2} \mathrm{O}$ and $2.5 \%$ triisopropylsilane (TIS) at ambient temperature for $3 \mathrm{~h}$, after which time the solvent was removed under reduced pressure and cold diethyl ether was added to precipitate the crude peptide. The precipitate was centrifuged at $4^{\circ} \mathrm{C}$ for $15 \mathrm{~min}(3000 \mathrm{rpm})$, the ether was decanted, and the crude solid was dried under high vacuum before being dissolved in a minimum amount of $\mathrm{H}_{2} \mathrm{O} / \mathrm{MeOH}$ and purified by RP-HPLC using an appropriate linear gradient of acetonitrile (A) and $0.1 \%$ (v/v) TFA $/ \mathrm{H}_{2} \mathrm{O}$ (B) (typically $3-20 \%$ A over $20 \mathrm{~min}, 20-100 \% \mathrm{~A}$ over $10 \mathrm{~min}$ ). The purity and identity of each peptide was determined by RP-HPLC (single peak) and FABMS, respectively (Table S1).

\footnotetext{
${ }^{2}$ Arano et al. J. Med. Chem. 1996, 39(18), 3451 - 3460.

${ }^{3}$ Williams, M. A.; Rapoport, H. J. Org. Chem. 1993, 58, $1151-1158$.
} 
Table S1. MS Data for Peptides Used in this Study

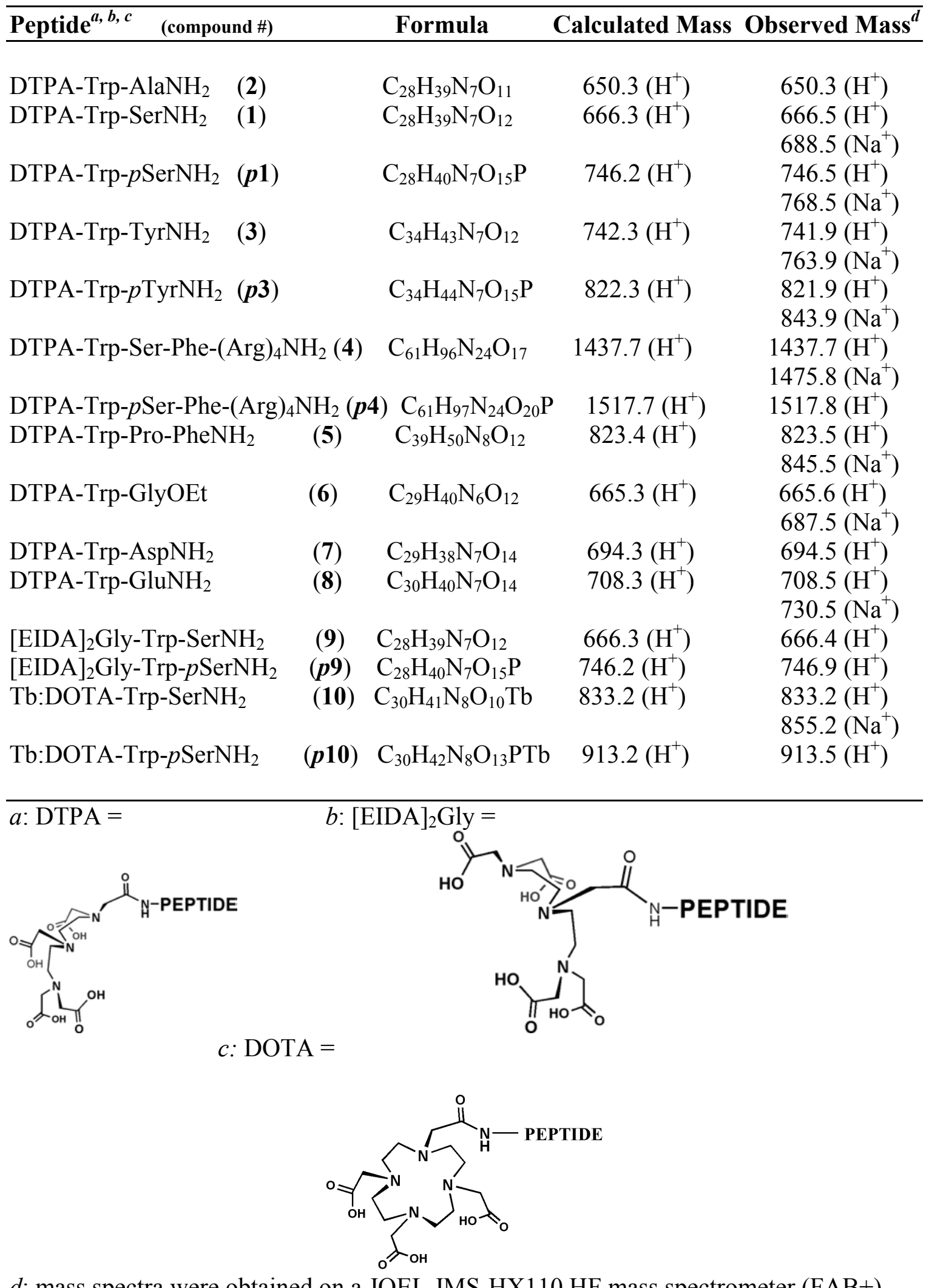

$d$ : mass spectra were obtained on a JOEL JMS-HX110 HF mass spectrometer $(\mathrm{FAB}+)$. 


\section{Part II: Steady State Emission Measurements}

\section{General}

Ultraviolet spectra were measured on a Molecular Devices SPECTRAmax Plus 384 UVVisible spectrophotometer operated through a Dell Pentium PC by SOFTmax software. Steady state emission/excitation measurements were taken on a Jobin Yvon Fluorolog fluorescence spectrofluorometer. Emission and excitation slit widths were 3-4 nm (HV = 750 ) using an excitation wavelength of $280 \mathrm{~nm}$ and scanning an emission window of 350 $600 \mathrm{~nm}$; scattered second order excitation light $(560 \mathrm{~nm})$ was avoided using a $390 \mathrm{~nm}$ long pass filter ${ }^{4}$.

Buffers and stock solutions of peptides and $\mathrm{Tb}^{3+}$ were prepared in de-ionized water (Millipore Simplicity 185, 18.2 M $)$ ). Peptide stock solutions (1-2 mM) were prepared by dissolution of lyophilized samples weighed on a microbalance, except solutions of the tetra-arginine containing peptides DTPA- $(p) \operatorname{SFRRRR}(\mathbf{4}, \boldsymbol{p 4})$, whose concentrations were determined using tryptophan absorbance. Stock solutions of $\mathrm{Tb}^{3+}(5-$ $10 \mathrm{mM}$ ) were prepared from $\mathrm{TbCl}_{3} \cdot 6 \mathrm{H}_{2} \mathrm{O} .^{5}$

\section{$\mathbf{T b}^{3+}$ Titrations}

Solutions of DTPA-peptide conjugates in pure water or buffer (concentrations typically from $1-100 \mu \mathrm{M}$ ) were excited at $280 \mathrm{~nm}$ and their emission was measured from $350-$ $600 \mathrm{~nm}$ before and after the addition of various equivalents of $\mathrm{TbCl}_{3}$ (typically $0-3$ equiv.). Experiments denoted as "continuous" were performed as follows: a cuvette equipped with a magnetic stir bar was gently mixed while aliquots ( 0.1 equiv.) of a 5 or $10 \mathrm{mM} \mathrm{TbCl}_{3}$ solution were added; full emission spectra were measured at each point after an appropriate equilibration time $(\sim 1 \mathrm{~min})$. Experiments denoted as "discontinuous" were performed as follows: various equivalents of $\mathrm{TbCl}_{3}$ were added to $500 \mu \mathrm{L}$ aliquots of DTPA-peptide conjugate solutions in water or buffer $(50-100 \mu \mathrm{M})$ and the volumes were normalized by the addition of the appropriate amount of water or buffer. After $3 \mathrm{~h}$, spectra were measured. In all cases, data obtained by the discontinuous method was in good agreement with data obtained in continuous experiments. Continuous titration endpoints were equilibrated for $>12 \mathrm{~h}$ and remeasured; spectra obtained were identical to data obtained from the continuous titration experiment. Data are corrected for concentration changes due to the volume of titrant added.

\footnotetext{
${ }^{4}$ As a result of this filter, tryptophan emission is truncated such that the maximum is shifted to $390 \mathrm{~nm}$.

${ }^{5} \mathrm{TbCl}_{3} \cdot 6 \mathrm{H}_{2} \mathrm{O}$ is a hygroscopic solid; only freshly opened bottles were used for preparing stock solutions, which were kept frozen during storage.
} 


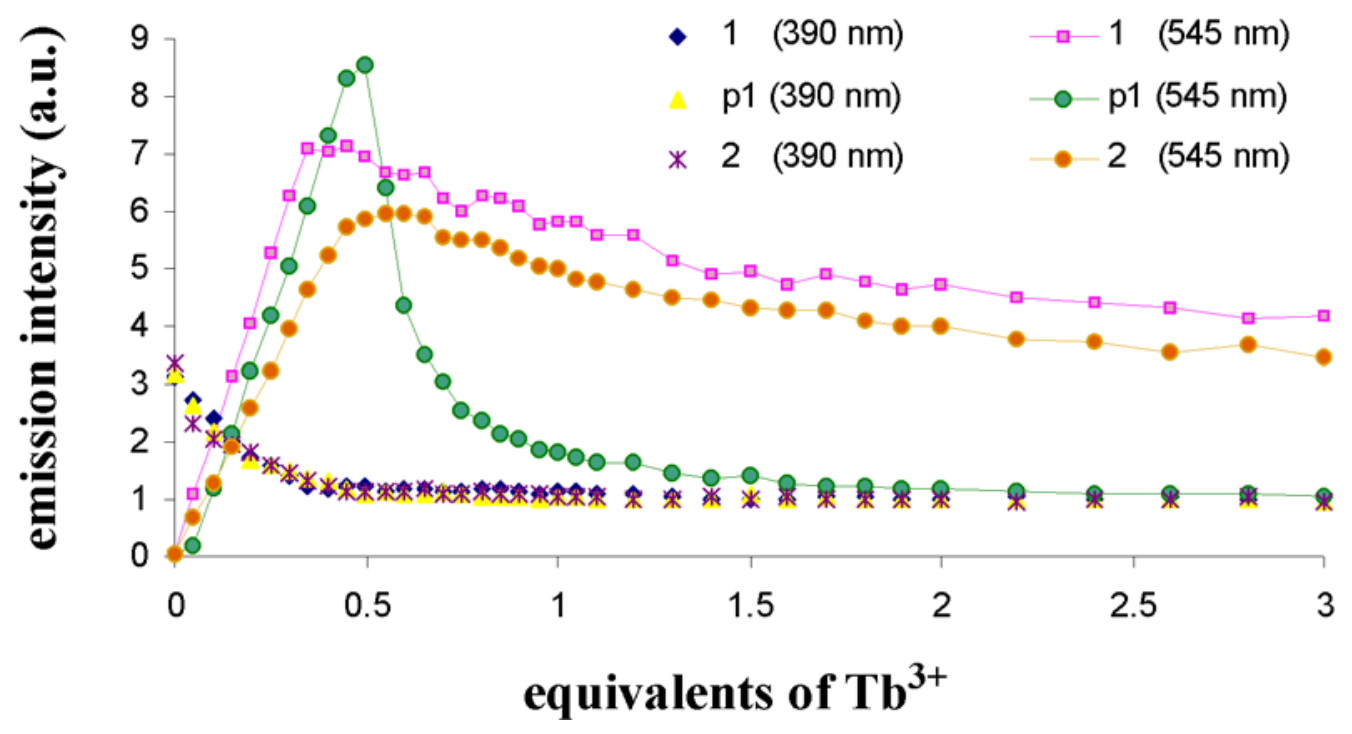

Figure S1. Continuous titration of substrates DTPA-TrpAlaNH $2(\mathbf{2}), \mathbf{1}$, and $\boldsymbol{p 1}$. $(100 \mu \mathrm{M}$, DI $\mathrm{H}_{2} \mathrm{O}, 25^{\circ} \mathrm{C}$; excitation at $280 \mathrm{~nm}$, emission monitored at $545 \mathrm{~nm}$ ).

\section{Effect of Added Salt}

The inflection point in the titration curve of $\boldsymbol{p} \mathbf{1}$ became less pronounced as the ionic strength of the solution was increased $\left(\mathrm{NaCl} / \mathrm{DI} \mathrm{H}_{2} \mathrm{O}\right)$ (Figure $\mathrm{S} 2$ ). In addition, the maximum shifted slightly to higher $\left[\mathrm{Tb}^{3+}\right]$ as ionic strength increased. Analogous titrations in HEPES $(10 \mathrm{mM})$ and HEPES/ $\mathrm{NaCl}(10 \mathrm{mM} / 100 \mathrm{mM})$ buffers showed similar shifting of the maximum.

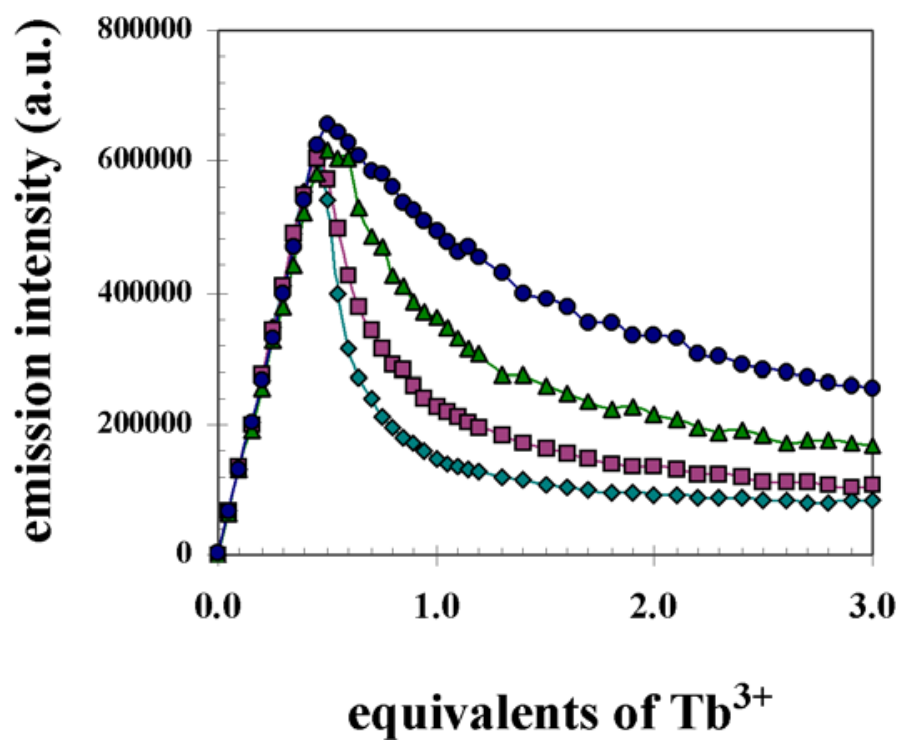

Figure S2. The effect of ionic strength variation on substrate $p \mathbf{1}$ titration data. Conditions: 0 (teal), 50 (purple), 150 (green), or 900 (dark blue) $\mathrm{mM} \mathrm{NaCl}$ in water, 50 
$\mu \mathrm{M}$ substrate; Excitation: $280 \mathrm{~nm}$, Emission: $545 \mathrm{~nm}$. [data shown are the average of two duplicate experiments, uncertainty $<5 \%]$.

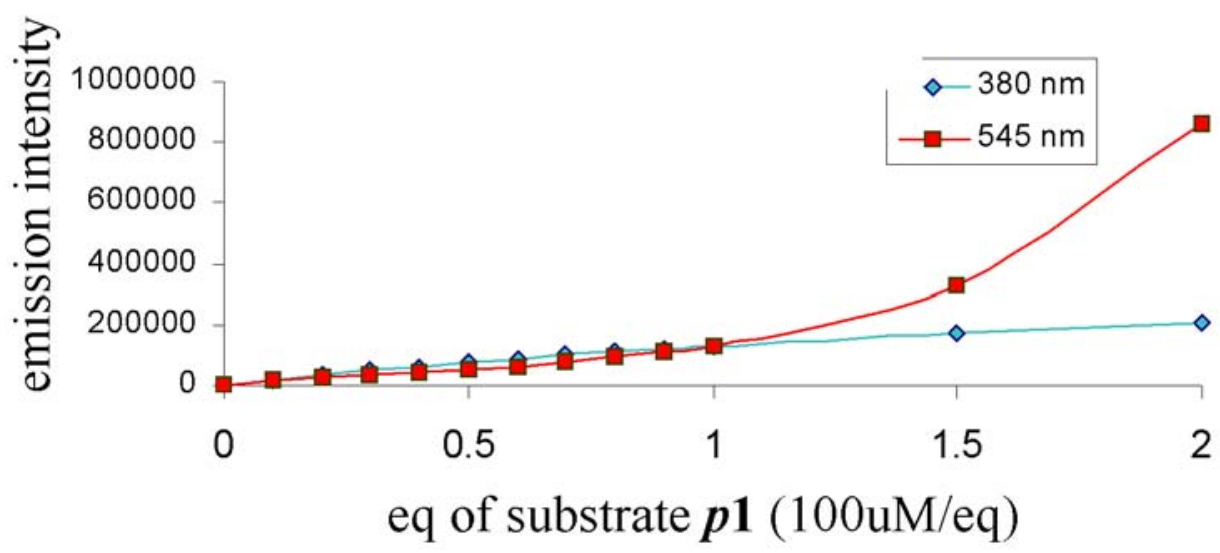

Figure S3. Reverse Titration: $\mathrm{Tb}^{3+}(100 \mu \mathrm{M})$ titrated with substrate $\boldsymbol{p} \mathbf{1}$ in water at $25^{\circ} \mathrm{C}$ (continuous titration). Excitation: $280 \mathrm{~nm}$, Emission: $380 \mathrm{~nm}$ and $545 \mathrm{~nm}$.

\section{Other chelate motifs}

The related acyclic chelate EIDA $_{2}$ Gly (see Table S1 $(b)$ ) and the kinetically stable ${ }^{6}$ macrocyclic ligand 1,4,7,10-tetraazacyclododecane-N,N',N",N"'-tetraacetic acid (DOTA) appended to Trp-SerNH ${ }_{2}$ (9 and 10, respectively) and Trp- $p \mathrm{SerNH}_{2}$ ( $\boldsymbol{p} \mathbf{9}$ and $\boldsymbol{p} \mathbf{1 0}$, respectively) dipeptides were also investigated; their $\mathrm{Tb} / \mathrm{Trp}$ ratios (emission at 545 $\mathrm{nm} / 390 \mathrm{~nm}$ ) are shown in Figure S4. The DOTA analogues demonstrate no significant difference between Ser and $p$ Ser derivatives. The DOTA analogues were stable to RPHPLC and were isolated as the $1: 1 \mathrm{~Tb}^{3+}$ complexes and their luminescence was not affected by the addition of excess $\mathrm{Tb}^{3+}$ or excess free ligand.

\footnotetext{
${ }^{6}$ Alexander, V. Chem. Rev. 1995, 95, $273-342$.
} 


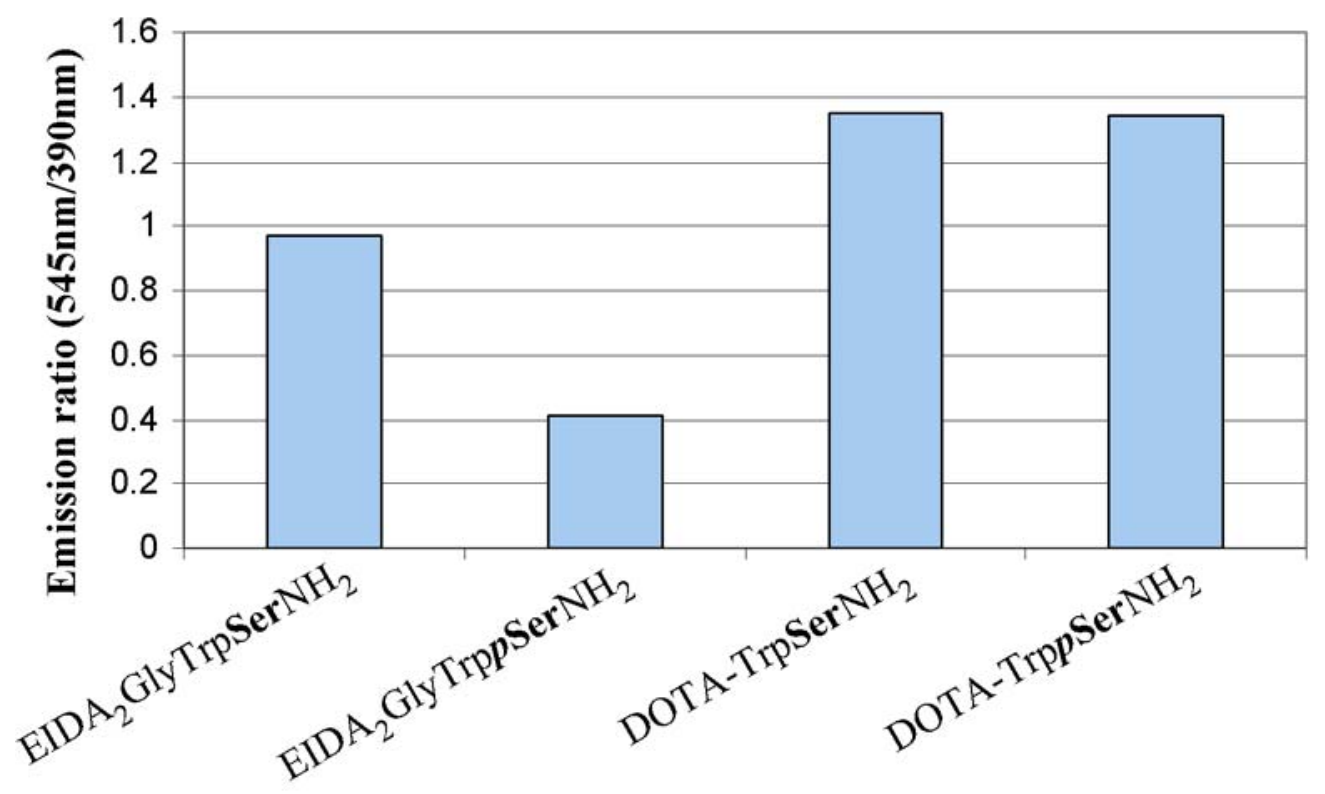

Figure S4. Tb/Trp emission ratios for $-\mathrm{Trp}-(p) \mathrm{SerNH}_{2}$ dipeptides appended to alternate chelate motifs. Conditions: $50 \mu \mathrm{M}$ in de-ionized water, $100 \mu \mathrm{M} \mathrm{Tb}^{3+}, 25^{\circ} \mathrm{C}$.

\section{Part III: Time Resolved Emission Measurements}

Time resolved experiments were performed on an OB900 single-photon counting Fluorometer (Edinburgh Analytical Instruments) with a pulsed Xenon microsecond lamp ( $\mu$ F900) as excitation source (pulse half width ca. $6 \mu \mathrm{s}$ ) in $4 \mathrm{~cm}^{2}$ quartz cells. Lifetime parameters were obtained with an Edinburgh software included with the instrument (F900 v6.42).

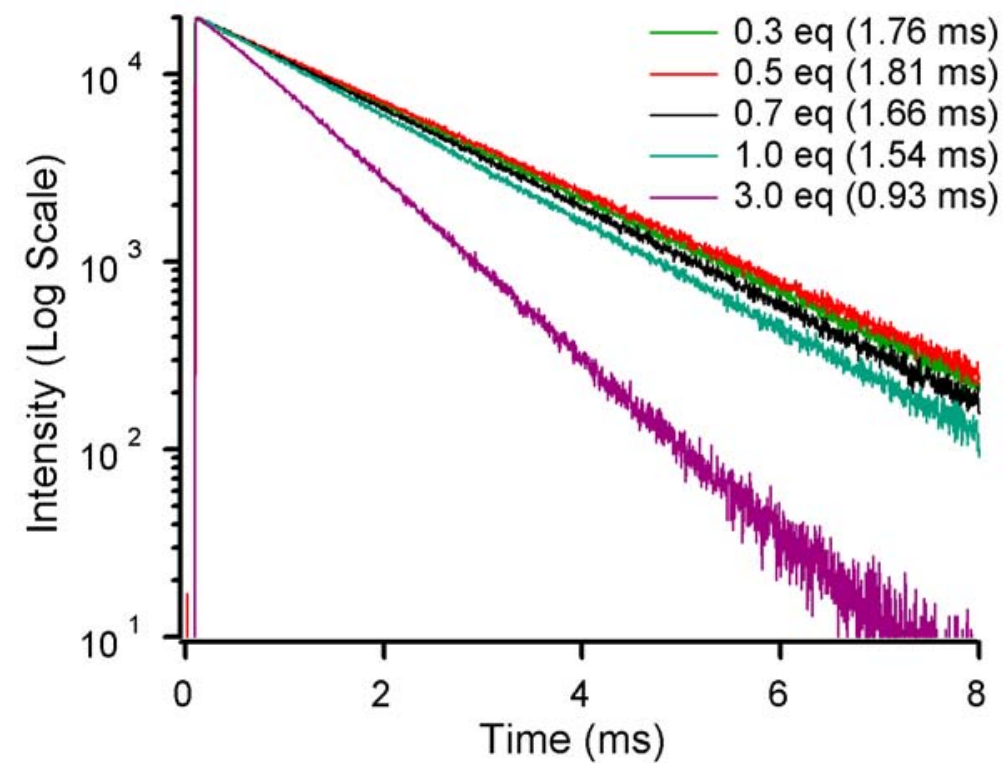


Figure S5. Luminescence decay curves for 1 at different $\mathrm{Tb}^{3+}$ concentrations. All the curves show a monoexponential decay with a decrease in lifetime with the increase of the $\mathrm{Tb}^{3+}$ concentration.

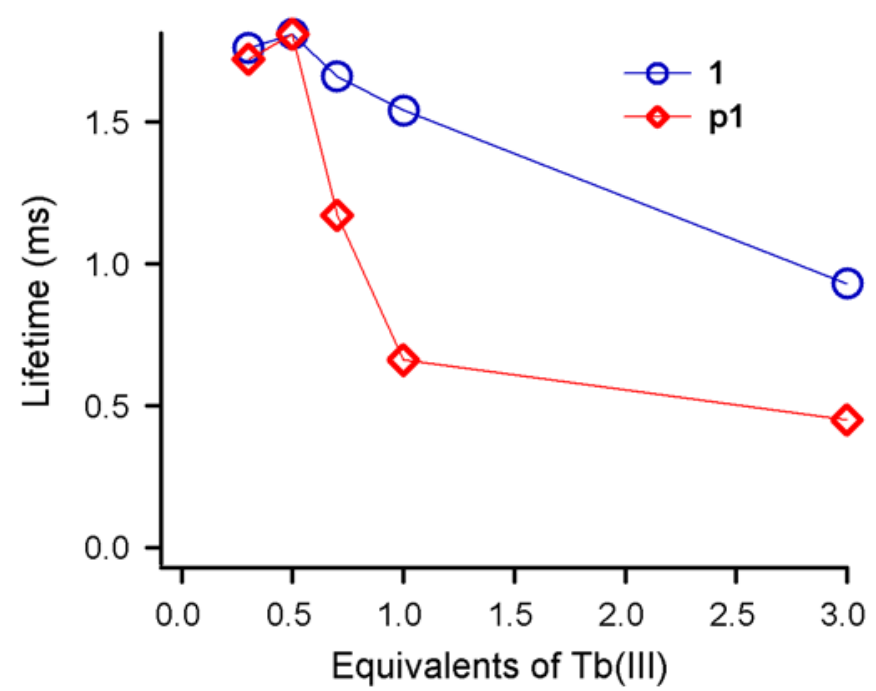

Figure S6. Average luminescence lifetimes of $\mathbf{1}$ and $\boldsymbol{p} \mathbf{1}$ as a function of the $\mathrm{TbCl}_{3}$ concentration. The figure shows a gradual decrease in the lifetime for $\mathbf{1}$, but a sharp decrease in the lifetime for $\boldsymbol{p} \mathbf{1}$ after the addition of 0.5 equivalents. The titration curves derived from luminescence lifetimes follow the same trend as the titration curves from steady-state luminescence intensities (Figure 1c).

\section{Part IV: ${ }^{31}$ P NMR Titrations}

Solutions of DTPA-Trp- $p \mathrm{SerNH}_{2}(\boldsymbol{p} \mathbf{1})$ and DTPA-Trp- $p \mathrm{TyrNH}_{2}(\boldsymbol{p 3})\left(5 \mathrm{mM}\right.$ in $\left.\mathrm{D}_{2} \mathrm{O}\right)$ were adjusted to pD $6-7$ using NaOD (4 wt. \%) and ${ }^{31} \mathrm{P}$ NMR was measured at 121 or $161 \mathrm{MHz}$ in the presence of various amounts of $\mathrm{Tb}(\mathrm{OTf})_{3}$ or $\mathrm{Eu}(\mathrm{OTf})_{3}$. The triflate salts were used in place of the chloride salts so that the $\mathrm{pD}$ was relatively unaffected by lanthanide addition. Integration and chemical shift are reported relative to a capillary containing $4.3 \% \mathrm{H}_{3} \mathrm{PO}_{4} / \mathrm{D}_{2} \mathrm{O}(\delta 0.0 \mathrm{ppm})$ as an external reference. For DTPA-Trp$p \mathrm{SerNH}_{2}$ (p1), the region from 90 to $-110 \mathrm{ppm}$ was scanned, but no peaks were observed outside of the region shown in Figure S7a. Parallel experiments with $\mathrm{Tb}^{3+}$ and $\mathrm{Eu}^{3+}$ are summarized in Figure S7b. A similar experiment with DTPA-Trp- $p \operatorname{TyrNH}_{2}$ (p3), scanned from 10 to $-60 \mathrm{ppm}^{7}{ }^{7}$ is shown in Figure S8. It is important to note that proximity to $\mathrm{Tb}^{3+}$, not only direct coordination to it, may result in extreme broadening or disappearance of ${ }^{31} \mathrm{P}$ NMR peaks. While the model proposed in the manuscript insinuates that phosphate coordination may play a more important role in the monomeric complex $(\boldsymbol{p} \mathbf{1}) \mathbf{T b}$, we cannot rule out the possibility of phosphate coordination in the dimeric configuration $(\boldsymbol{p} \mathbf{1})_{2} \mathbf{T b}$ based on ${ }^{31} \mathrm{P}$ NMR data, since only the free ligand $\boldsymbol{p} \mathbf{1}$ has an observable peak. However, the near-degenerate luminescence of $(\boldsymbol{p} \mathbf{1})_{2} \mathbf{T b}$ and $(\mathbf{1})_{2} \mathbf{T b}$

\footnotetext{
${ }^{7}$ This scan windown brackets the region reported for phosphotyrosine bound to $\mathrm{Tb}^{3+}$ in $\alpha$-synuclein peptides: Liu, L. L. and Franz, K. J. J. Am. Chem. Soc. 2005, 127, 9662 - 9663.
} 
(for example, Figure 1c at 0.5 equivalents of $\mathrm{Tb}^{3+}$ added) suggests that phosphate coordination may not be important in the dimer configuration.

$\mathbf{a}$

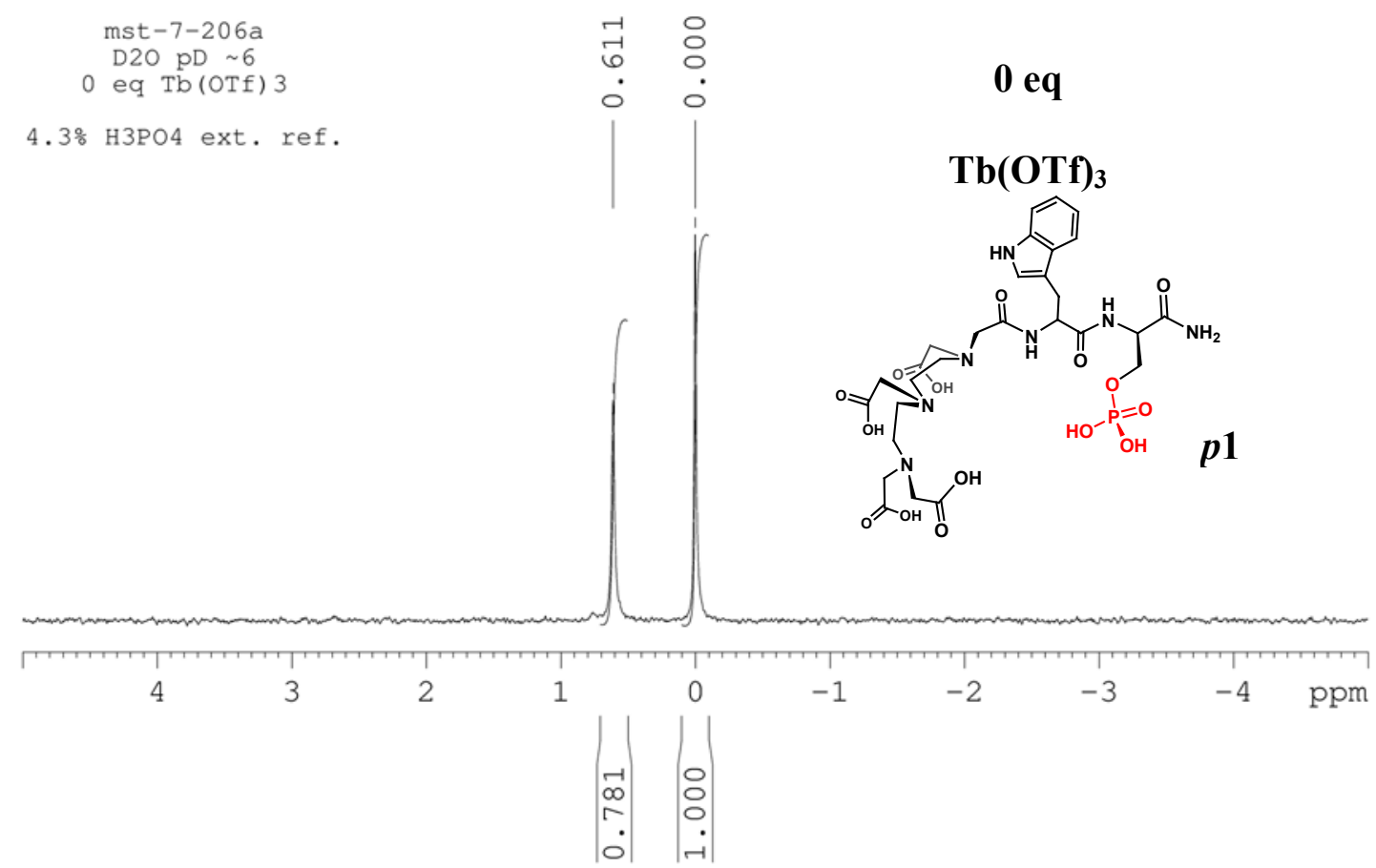

mst $-7-206 \mathrm{~b}$
$\mathrm{D} 20 \mathrm{pD} \sim 6$
0.2 eq Tb(OTF) 3

4.3\% H3PO4 ext. ref.

$\begin{array}{ll} & 0 \\ -1 & \circ \\ \text { m. } & 0 \\ 0 & 0\end{array}$

0.2 eq
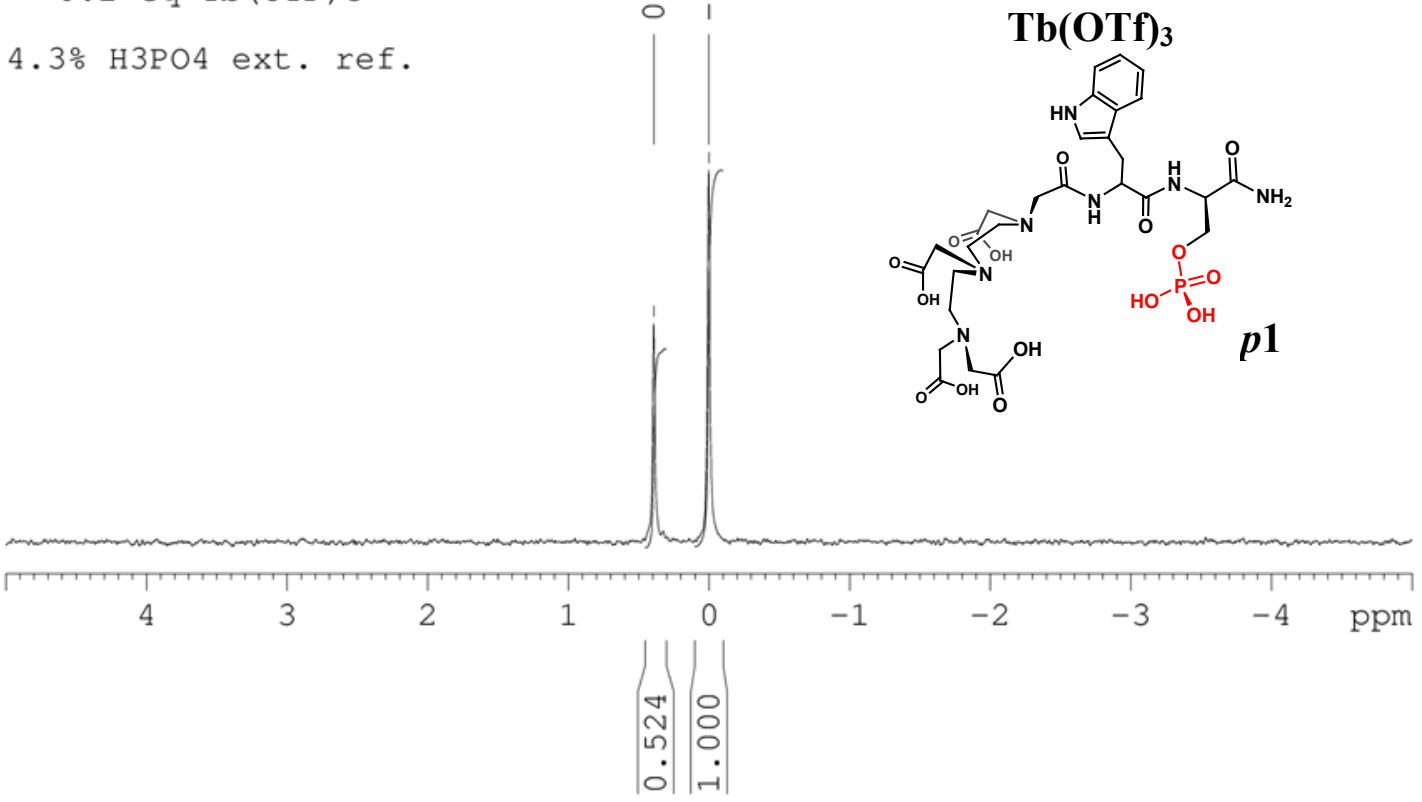
$\mathbf{a}$ (cont'd)

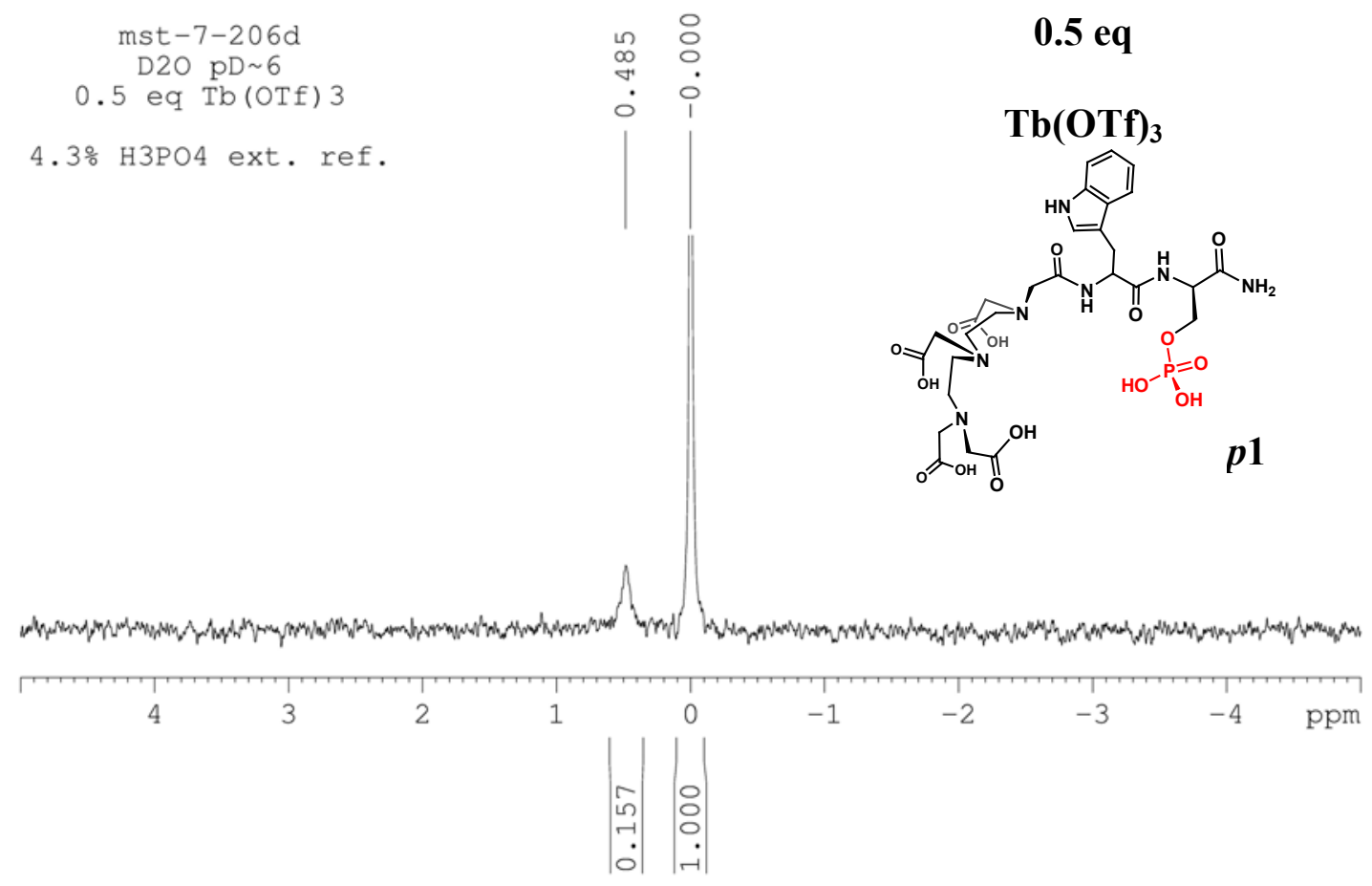




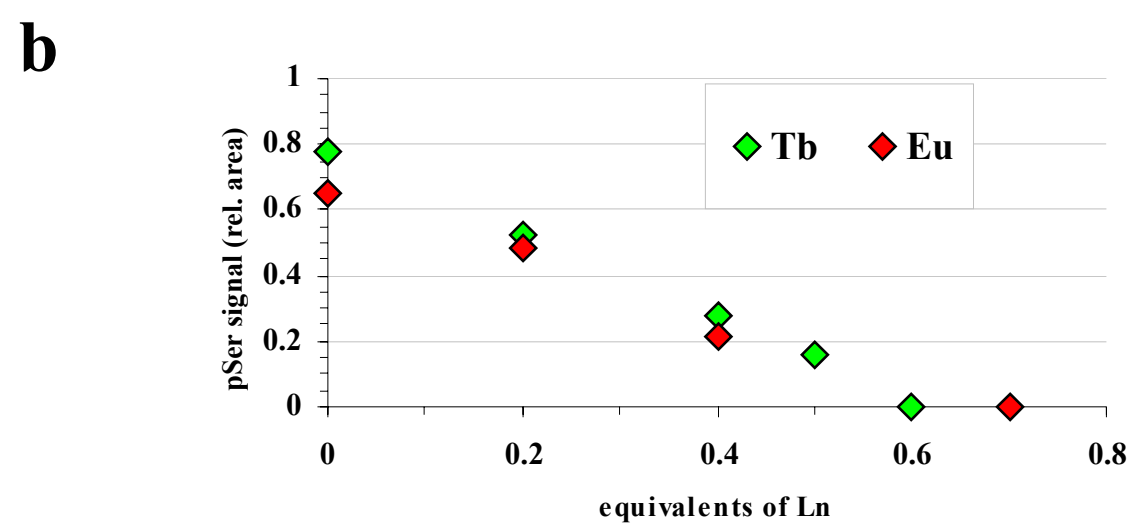

Figure S7. ${ }^{31} \mathrm{P}$ NMR spectra of DTPA-Trp- $p \mathrm{SerNH}_{2}(\boldsymbol{p} \mathbf{1})$ in the presence of various equivalents of $\mathrm{Tb}(\mathrm{OTf})_{3}$ or $\mathrm{TbCl}_{3}$ (a). ${ }^{31} \mathrm{P}$ integrations in the presence of various equivalents of $\mathrm{Tb}(\mathrm{OTf})_{3}$ and $\mathrm{Eu}(\mathrm{OTf})_{3}$. 

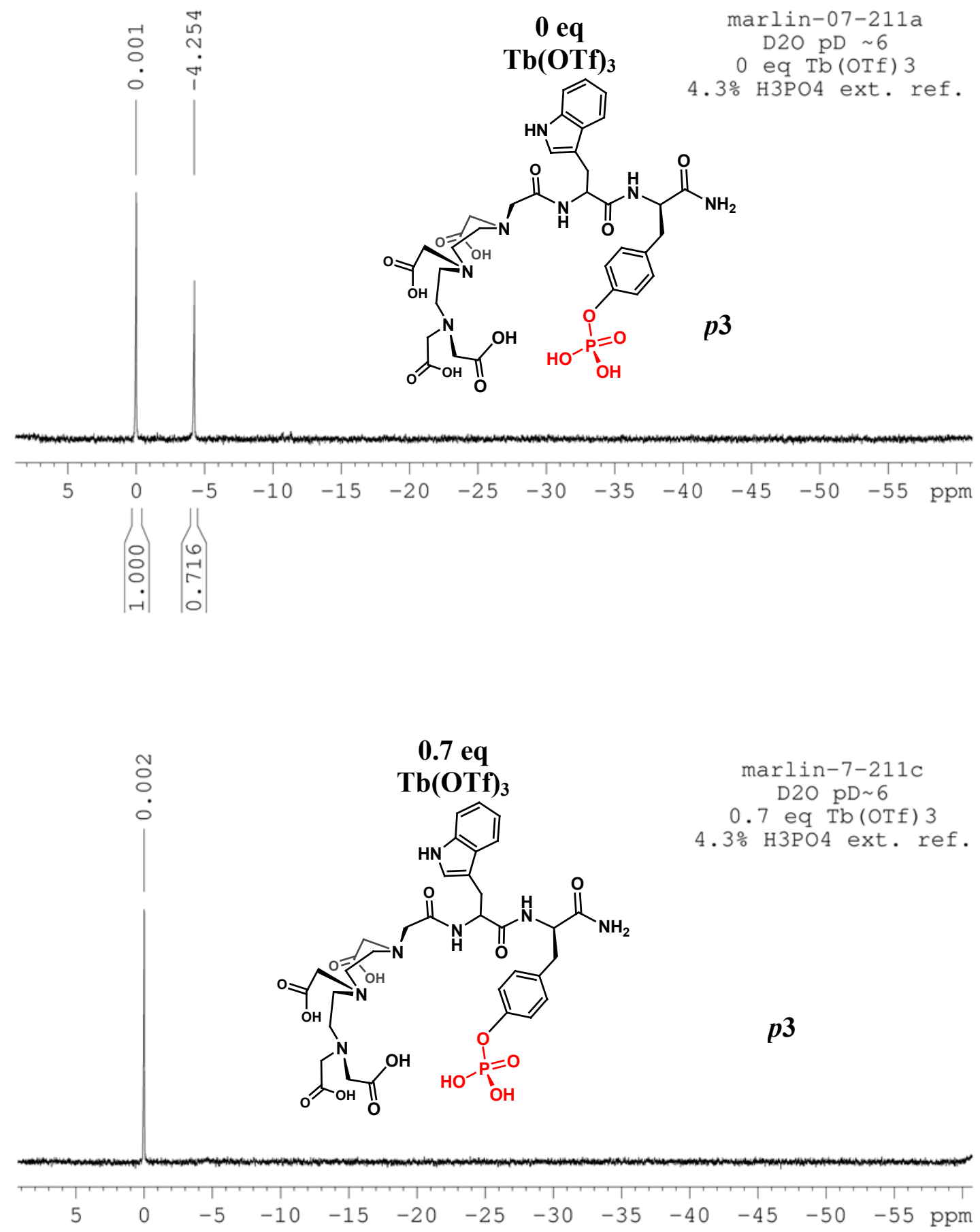

Figure S8. ${ }^{31} \mathrm{P}$ NMR spectra of DTPA-Trp- $p \mathrm{TyrNH}_{2}(\boldsymbol{p 3})$ in the presence of various equivalents of $\mathrm{Tb}(\mathrm{OTf})_{3}$ 


\section{Part V: Mass Spectrometry}

Identification of oligomeric species by mass spectrometry was unsuccessful. Samples containing $\mathbf{1}, \boldsymbol{p} \mathbf{1}$, and $\mathbf{2}$ and $\mathrm{TbCl}_{3}$ in a 2:1 ratio (prepared at $\mathrm{pH} 6$ and subsequently lyophilized) were ionized by ESI-MS, FAB-MS, and MALDI-TOF, but all spectra showed only the monomeric $\mathrm{Tb}$ complex and free peptide. When $\boldsymbol{p} 1$ was complexed with 1 equivalent of $\mathrm{TbCl}_{3}$, the monomeric $\mathrm{Tb}$ complex and $n o$ free peptide was observed. Data for $\boldsymbol{p} \mathbf{1}$ is shown in Table S2.

Table S2. Mass spectroscopy data for $\boldsymbol{p 1}$ in the presence of $\mathrm{Tb}^{3+}$.

\begin{tabular}{|c|c|c|c|}
\hline & $\begin{array}{c}\boldsymbol{p 1} \\
\text { (no } \mathrm{Tb}^{3+} \text { added) }\end{array}$ & $\begin{array}{c}\text { (p1) } \mathbf{T b} \\
\left(1.0 \text { eq. } \mathrm{Tb}^{3+} \text { added }\right)\end{array}$ & $\begin{array}{c}(\boldsymbol{p} \mathbf{1})_{2} \mathbf{T b} \\
\left(0.5 \text { eq. } \mathrm{Tb}^{3+} \text { added }\right)\end{array}$ \\
\hline Calculated $(\mathrm{m} / \mathrm{z})$ & $746.2\left(\mathrm{H}^{+}\right)$ & $902.1\left(\mathrm{H}^{+}\right)$ & $1647\left(\mathrm{H}^{+}\right)$ \\
\hline Observed $\left({ }^{m} / z\right)$ & $746.6\left(\mathrm{H}^{+}\right)$ & $902.6\left(\mathrm{H}^{+}\right)$ & $\begin{array}{c}746.6\left(\mathrm{H}^{+}\right) \\
(0.85 \text { rel. intensity) } \\
902.6\left(\mathrm{H}^{+}\right) \\
(1.00 \text { rel. intensity) }\end{array}$ \\
\hline
\end{tabular}

\section{Part VI: Enzyme Assays}

A stock solution of alkaline phosphatase (Sigma P-7640; EC 3.1.3.1; activity $~ 13$ units $/ \mathrm{mg}$ ) was prepared in de-ionized water at a concentration of 1.3 units $/ \mathrm{mL}$. To initiate reaction $1.67 \mu \mathrm{L}$ of this stock solution was added to a solution containing DTPATrp- $p \mathrm{SerNH}_{2}$ (p1) or DTPA-Trp- $p \mathrm{TyrNH}_{2}(\mathbf{p 3})(25 \mu \mathrm{M})$ and $\mathrm{TbCl}_{3}(0,13,25$, or $38 \mu \mathrm{M})$ in HEPES buffer ( $10 \mathrm{mM}$ HEPES, $100 \mathrm{mM} \mathrm{NaCl}, \mathrm{pH} 7.4)$. After incubation at $37^{\circ} \mathrm{C}$, the emission spectrum was measured. The reaction could be performed with 1.5 equivalents of $\mathrm{TbCl}_{3}(38 \mu \mathrm{M})$ and monitored continuously by measuring the increasing ratio of $\mathrm{Tb}$ luminescence $(544 \mathrm{~nm})$ to tryptophan fluorescence $(390 \mathrm{~nm})$.

In order to assess the effect of $\mathrm{Tb}^{3+}$ on the activity of alkaline phosphatase, as well as the ability of different compositions of monomeric/oligomeric species to act as suitable substrates, we performed control experiments in which the reaction was performed with 0 equivalents $(0 \mu \mathrm{M}), 0.5$ equivalents $(13 \mu \mathrm{M})$, or 1.0 equivalents $(25 \mu \mathrm{M})$ of $\mathrm{TbCl}_{3}$. For these assays, reaction progress was monitored discontinuously by removing an aliquot from the reaction, adjusting the $\mathrm{TbCl}_{3}$ concentration to $38 \mu \mathrm{M}$, and immediately measuring the emission ratio of $544 \mathrm{~nm} / 390 \mathrm{~nm}$ (Figure S9). Initial rates were nearly identical $(<20 \mathrm{~min}$.$) ; at longer reaction times, a modest, \left[\mathrm{Tb}^{3+}\right]$-dependent rate enhancement was observed, which is known to occur for alkaline phosphatase. ${ }^{8}$ Phosphate hydrolysis did not occur in the presence of $\mathrm{Tb}^{3+}$ unless alkaline phosphatase was added.

\footnotetext{
${ }^{8}$ Sherry, A. D.; Au-Young, S.; Cottam, G. L. Arch. Biochem. Biophys. 1978, 189, 277 - 282.
} 
Control experiments were performed by incubating solutions of the phosphorylated peptides without enzyme under the same conditions (negative) and by incubating the dephosphorylated peptides with and without enzyme under the same conditions (positive) (Figure S10). After the assay, some samples were frozen and lyophilized; the dried samples were redissolved in $50 \%$ acetonitrile/0.1\%TFA and analyzed by MALDI-TOF MS in the linear mode on an Applied Biosystems Voyager DE Pro with $\alpha$-cyano-4-hydroxycinnamic acid matrix $\left(10^{\mathrm{mg}} / \mathrm{ml}\right)$ (Figures S11, S12).

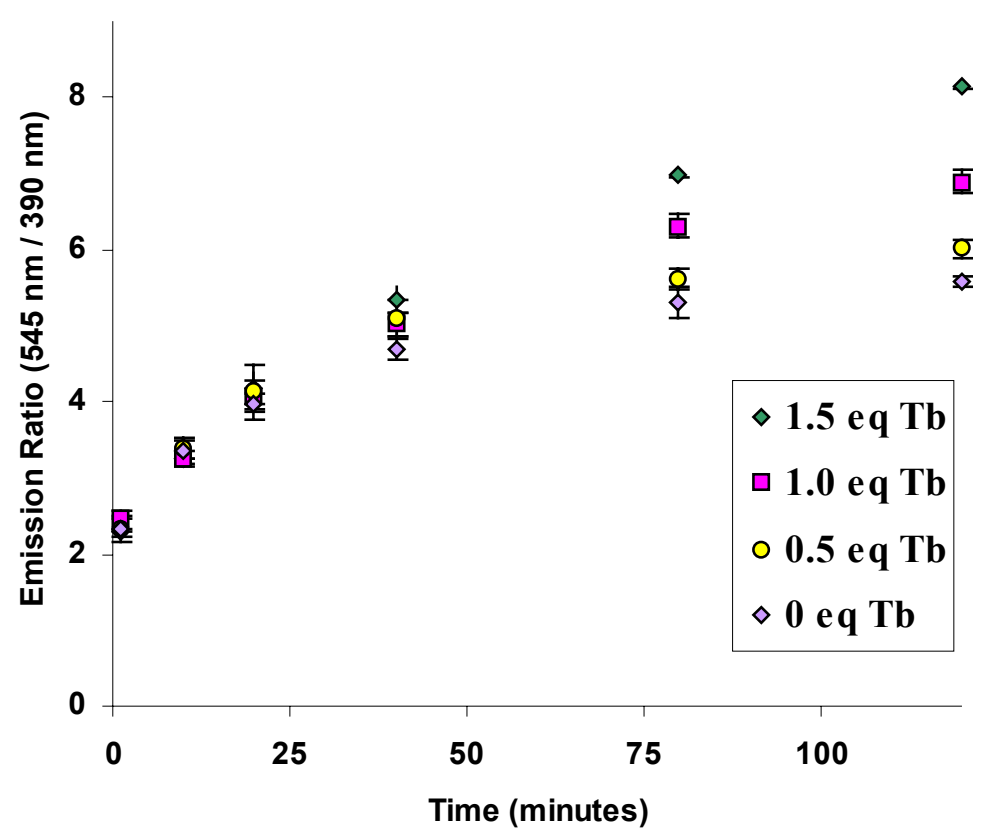

Figure S9. Alkaline phosphatase assay of DTPA-Trp- $(p) \mathrm{SerNH}_{2}$ (p1) measured fluorometrically at different time points. All data points are measured with $38 \mu \mathrm{M} \mathrm{TbCl}_{3}$; equivalents of $\mathrm{Tb}$ refers to the concentration during the assay. Conditions: (vide supra). 

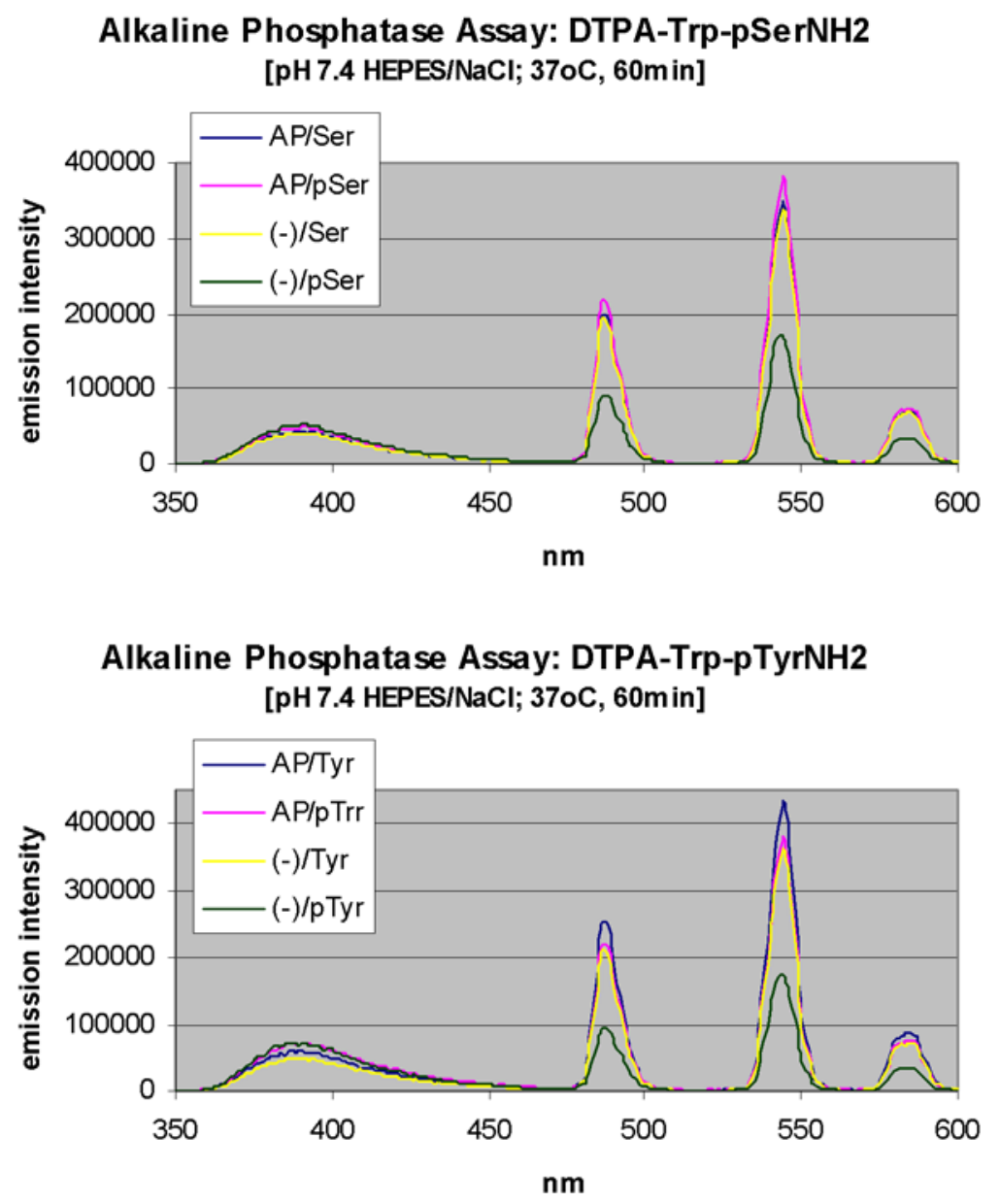

Figure S10. Alkaline phosphatase assay of DTPA-Trp- $(p) \mathrm{SerNH}_{2}(\boldsymbol{p} \mathbf{1})$ and DTPA-Trp$(p) \mathrm{TyrNH}_{2}$ showing $(+)$ and (-) controls. Conditions: (vide supra). 

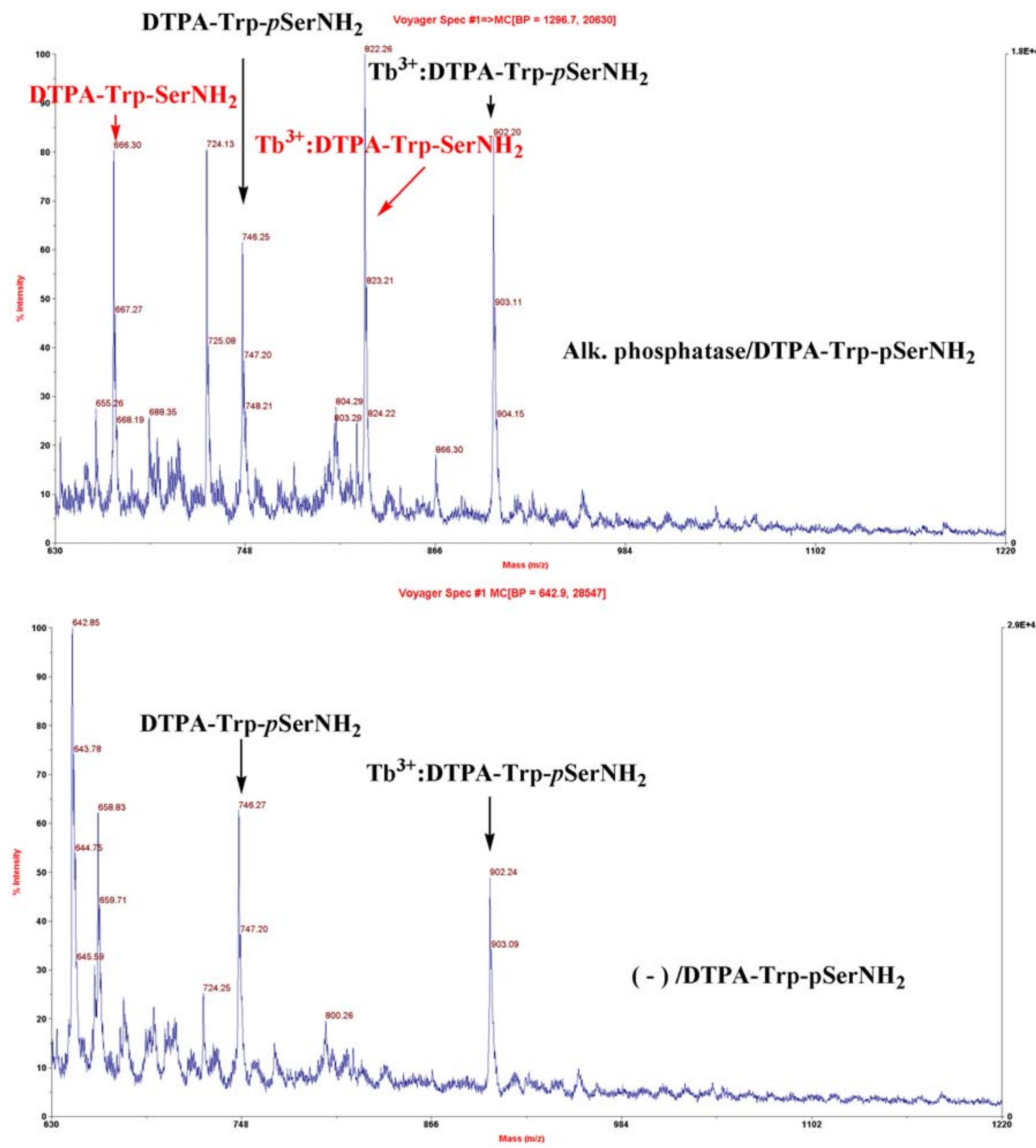

Figure S11. Mass spec. analysis of the crude dephosphorylation of DTPA-Trp- $p$ SerNH $\mathrm{N}_{2}$. Conditions: (vide supra). 

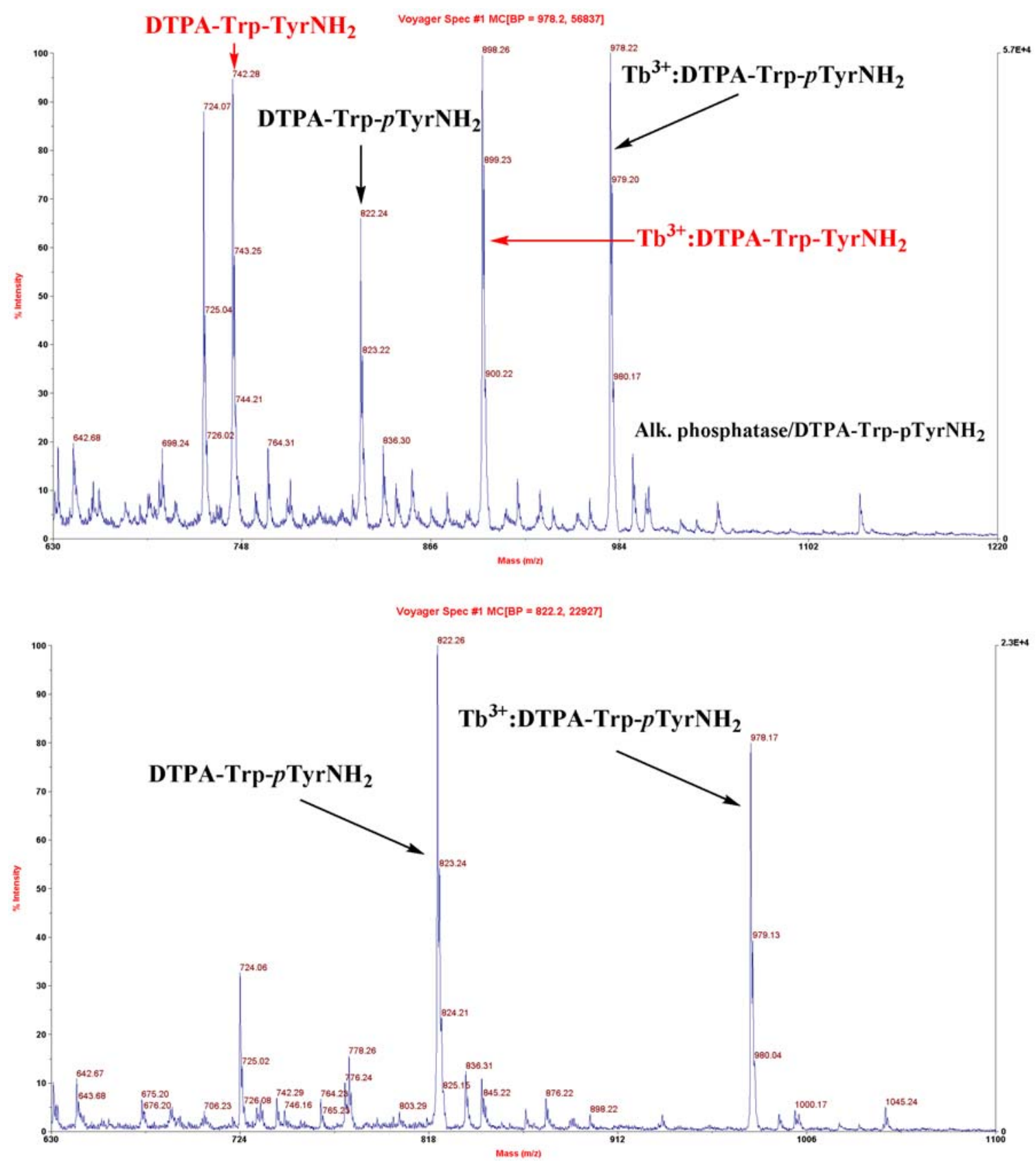

Figure S12. Mass spec. analysis of the crude dephosphorylation of DTPA-Trp- $p$ TyrNH${ }_{2}$. Conditions: (vide supra). 